\title{
Potencial mutagênico de um afluente do Rio Vaza-Barris (SE), por meio do sistema-teste micronúcleo (TMN) em molusco bivalve
}

Mutagenic potential of a tributary of the Vaza-Barris River, using micronucleus test systems (TMN) in bivalve mollusks

\author{
C. S. Santos ${ }^{1 *}$; D. S. S. Júnior ${ }^{1}$; J.S. Oliveira ${ }^{1}$; K. M. S. A. Castro ${ }^{1}$; M. B. J. \\ Feitosa $^{2}$; S. M. Pantaleão ${ }^{1}$
}

${ }^{1}$ Departamento de Biologia, Laboratório de Genética e Conservação de Recursos Naturais, Universidade Federal de Sergipe, 49100-000, São Cristóvão-Sergipe, Brasil

${ }^{2}$ Departamento de Fisiologia, Laboratório de Biologia Cardiovascular e Estresse Oxidativo, Universidade Federal de Sergipe, 49100-000, São Cristóvão-Sergipe, Brasil

*carolina15silveira@hotmail.com

(Recebido em 20 de junho de 2017; aceito em 28 de setembro de 2017)

\begin{abstract}
A poluição aquática da origem antropogênica é prejudicial aos ecossistemas e pode causar danos ao DNA dos indivíduos que vivem neles. O presente estudo teve como objetivo analisar o potencial mutagênico de poluentes no rio Paramopama, um afluente do rio Vaza Barris, utilizando o teste de micronúcleos (TMN) em Mytella falcata (Sururu), que detecta rupturas cromossômicas neste organismo experimental. Foram realizadas duas coleções, nos meses de agosto de 2015 e maio de 2016, nas quais foram preparadas lâminas de amostras de brânquias de $M$. falcata para a observação de micronúcleos. A freqüência de micronúcleos encontrados nas amostras variou de $6 \%$ a $23 \%$ ao longo do rio, demonstrando a presença de contaminantes com efeito mutagênico nas áreas estudadas do rio Paramopama.

Palavras-chave: Mytella falcata, mutagênese ambiental, Rio Paramopama.
\end{abstract}

Aquatic pollution of anthropogenic origin is harmful to ecosystems and may cause damage to the DNA of individuals living in them. The present study aimed to analyze the mutagenic potential of pollutants in the Paramopama River, a tributary of the Vaza Barris River, using the micronucleus test (TMN) in Mytella falcata (Sururu), which detects chromosomal breaks in this experimental organism. Two collections were carried out, in the months of August, 2015 and May, 2016, in which slides of samples of M. falcata gills were prepared for the observation of micronuclei. The frequency of micronuclei found in the samples ranged from $6 \%$ to $23 \%$ along the river, demonstrating the presence of contaminants with a mutagenic effect in the studied areas of the Paramopama River.

Keywords: Mytella falcata, environmental mutagenesis, Paramopama River.

\section{INTRODUÇÃO}

O impacto ambiental causado pelo crescimento urbano traz consequências negativas, principalmente para os recursos hídricos, uma vez que estes são o último destino de muitos poluentes, lançados diretamente em rios e córregos. Isto tem impactado esses ecossistemas, uma vez que muitos dos materiais lançados não são biodegradáveis e podem ser bioacumulados ou depositados nos ambientes aquáticos [1].

Um dos efeitos gerados pelas ações antrópicas no meio ambiente é o surgimento de micronúcleos em células animais. O micronúcleo $(\mathrm{MN})$ é formado no processo de divisão celular quando um cromossomo não se integra ao núcleo da nova célula, por material genético perdido ou danificado, sendo uma consequência de danos causados por agentes físicos, químicos ou biológicos [2]. O teste do micronúcleo (TMN) é um procedimento realizado para detectar efeitos clastogênicos (mutagênicos), ou seja, efeitos que danificam o cromossomo, ocasionando fragmentos ou cromossomos inteiros que foram perdidos durante a mitose, sendo muito utilizado para o monitoramento ambiental, que avalia a sua frequência em animais que residem em ambientes impactados $[3,4,5,6]$. 
O Rio Paramopama corresponde a um afluente do Rio Vaza-Barris. A bacia hidrográfica do Vaza-Barris nasce no município de Uauá (BA), tendo um comprimento total de $3.300 \mathrm{Km}$, nos quais apenas $152 \mathrm{~km}$, ou seja 15\%, se localizam no estado de Sergipe, beneficiando uma área total de $17.000 \mathrm{~km}^{2}$. No Estado abrange os municípios de Carira, Frei Paulo, Pedra Mole, Pinhão, Areia Branca, Campo do Brito, Itabaiana, Macambira, São Domingos, Simão Dias, Lagarto, Aracaju, São Cristóvão e Itaporanga D'ajuda [7].

Segundo Carvalho (2012) [8], essa bacia corresponde a uma área de elevado crescimento populacional, cuja ocupação ocorre de forma desordenada, provocando diversos impactos ambientais, não somente no corpo principal do rio, como também em seus afluentes, em virtude das ações antrópicas. O rio é utilizado para abastecimento público para a região, como também irrigação, pesca, dessedentação de animais e turismo. Em contrapartida, este rio é igualmente utilizado como receptor de efluentes industriais, domésticos e agroindustriais causando vulnerabilidade hídrica, onde são liberados diretamente efluentes sólidos e líquidos.

Os estudos realizados estão amplamente ligados ao Rio Vaza Barris, entretanto, seu afluente, o Rio Paramopama, é raramente estudado, não havendo pesquisas relacionadas a poluição biológica e caracterização de seus poluentes.

O mexilhão Mytella falcata, conhecido popularmente como Sururu, é um molusco bivalve encontrado em estuários (no caso, no Rio Paramopama) e de grande importância econômica, pois é utilizado na alimentação humana. Além disso, é um bom bioindicador de poluição ambiental devido ao seu hábito séssil e filtrador e, também à capacidade de acumular diversas substâncias presentes no ambiente em que está inserido.

Assim, este estudo objetivou determinar possíveis efeitos tóxicos do ambiente sobre organismos aquáticos residentes, Mytella falcata, no Rio Paramopama por meio do sistema TMN para análise de danos mutagênicos.

\section{MATERIAL E MÉTODOS}

A metodologia executada no presente estudo consistiu em selecionar diferentes pontos de um afluente do rio Vaza-barris, o rio Paramopama. Os critérios utilizados para demarcar os pontos de coleta se deram em razão da proximidade a cidade de São Cristóvão ao qual apresenta- se mais vulnerável a ações antrópicas. Sendo assim, o Ponto 1 está mais próximo a cidade e seus impactos ambientais que o Ponto 5. Foram realizadas coletas no mês de agosto (seco), e maio (chuvoso).

Uma coleta piloto foi realizada em junho de 2015, no rio Paramopama, com o objetivo de conhecer a localidade para estabelecer os pontos de coleta e testar a metodologia utilizada, a fim de se realizar as devidas adaptações ao animal em estudo. A primeira coleta foi realizada em agosto de 2015 e a segunda em maio de 2016.

Os pontos, conhecidos popularmente entre os pescadores na primeira coleta, correspondem ao

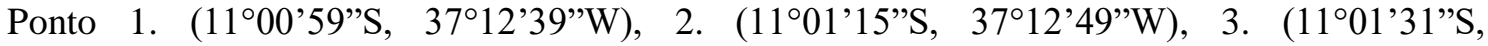

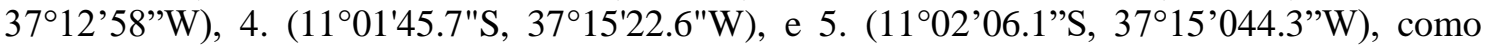
verificado na Figura 1. Na segunda coleta, os mesmos locais de coleta foram utilizados. 


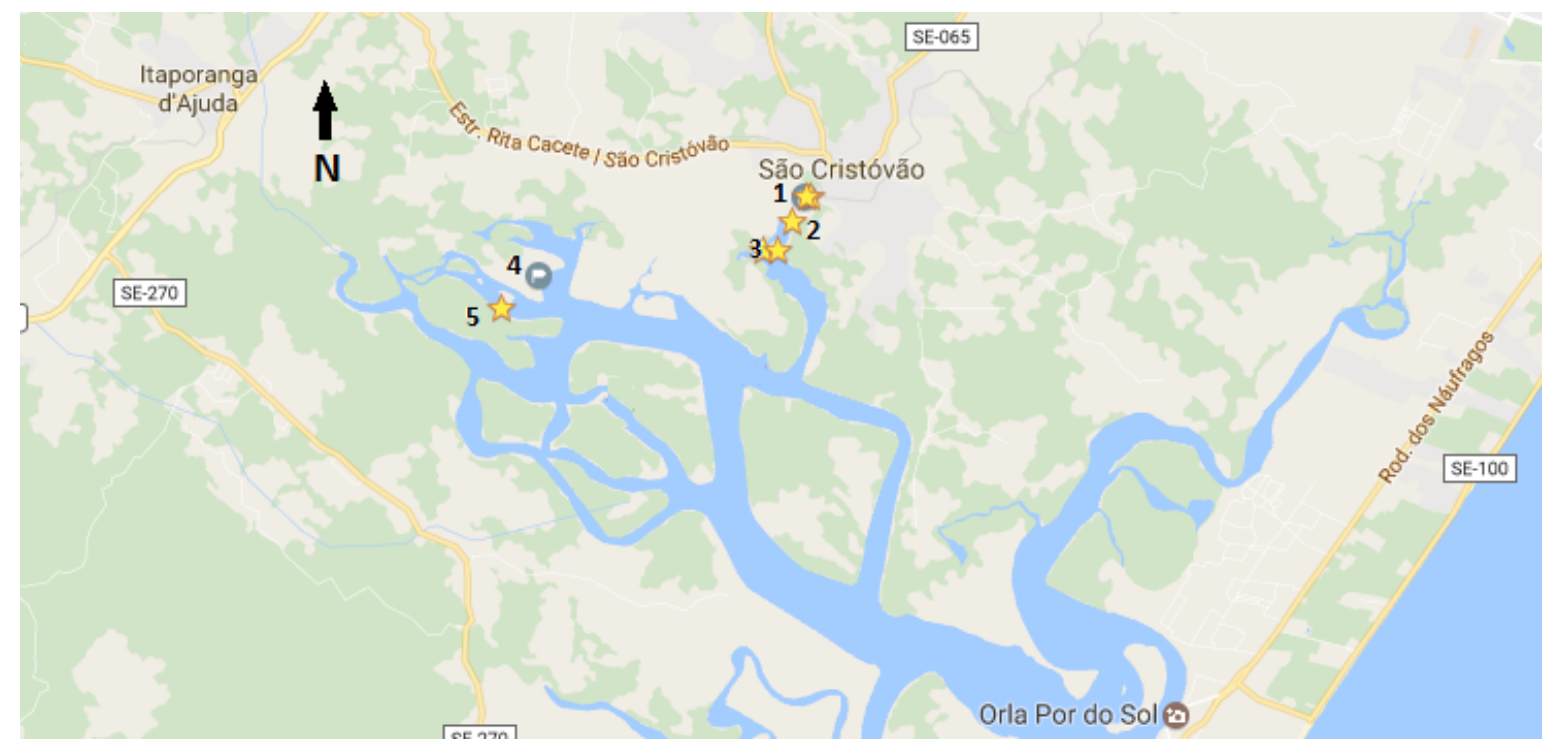

Figura 1: Localização do Rio Paramopama, São Cristóvão- SE. Fonte: Google Maps, marcadores adicionados pelos autores

Em cada ponto, foram coletados, no mínimo15 moluscos bivalves adultos, além de água e sedimento do local. As amostras de água e sedimento foram submetidas ao teste SMART em $D$. melanogaster, com análise ainda em andamento.

A metodologia utilizada neste estudo foi de Barsiene et al. (2015) [9] sendo adaptada para o organismo em estudo, Mytella falcata. As modificações tiveram como objetivo uma melhor visualização da célula e do micronúcleo. Os animais coletados foram dissecados e, em seguida, as brânquias extraídas. Foi utilizado, então, um tubo onde as brânquias foram maceradas com 3 gotas da mistura de ácido acético e etanol na proporção de 3:1 por mais ou menos 3 minutos. Em seguida, utilizando uma pipeta de $200 \mu \mathrm{L}$, espalhou-se o material na lâmina, obtendo o esfregaço que foi deixado secar à temperatura ambiente. As lâminas foram fixadas em metanol por 10 minutos e coradas com Giemsa (NEWPROV®) a $5 \%$ por 5 minutos. Na última coleta, modificouse a coloração para coloração panóptico, para melhor visualização das células.

Subsequentemente, as lâminas foram observadas ao microscópio óptico em objetiva de imersão. Foram confeccionadas uma lâmina por animal e cinco lâminas por ponto, contando-se 1.000 células por animal e 5.000 células por ponto.

A análise dos dados foi realizada por meio da obtenção da frequência de $\mathrm{MN}$ em cada ponto, utilizando-se a seguinte fórmula:

$\mathrm{Fmn}=\mathrm{nm} / \mathrm{nc} \times 100$

Sendo $(\mathrm{Fmn}=$ frequência de micronúcleos; $\mathrm{nm}=$ número de micronúcleos; $\mathrm{nc}=$ número de células analisadas).

As frequências das duas coletas foram comparadas para verificar se, no período chuvoso, a frequência de MN seria menor por haver diluição de agentes contaminantes. Para análise estatística, os resultados foram processados no software Prism 5.1 (GraphPad, San Diego, CA, EUA), Os dados foram analisados adotando-se o teste $t$ de Student, unicaudal, para verificar se a hipótese de que no período chuvoso, a frequência de MN seria menor por haver diluição de agentes contaminantes. A análise de variância ANOVA two-way para medidas paramétricas, seguidas do pós-teste de Bonferroni para comparação entre os grupos. Para efeito estatístico, serão considerados significativos os valores que apresentem $p<0,05$. 


\section{RESULTADOS E DISCUSSÃO}

A primeira coleta para análise, feita em agosto de 2015, mostrou no Ponto 1 uma frequência de 23\% de MN nas células analisadas. A frequência de MN no Ponto 2 foi de $17 \%$; no Ponto 3 de 18\%; no Ponto 4 de 12\%; e no Ponto 5, 14\%. Já na segunda coleta, período chuvoso, foram encontrados nestes pontos $16 \%, 6 \%, 6 \%, 4 \%$ e $10 \%$, respectivamente, como apresentado na Figura 2. Essa diferença sazonal reflete a diluição dos poluentes. Não houve diferença estatística entre os pontos observados no mesmo ano porém, ao se comparar o período seco ao chuvoso (2015 e 2016) observamos que o número total de MN encontrados foi significativamente diferentes, 39 e $16 \mathrm{MN}$, respectivamente.

No ano de 2016, o período de coleta (maio) reflete o mês cujo o índice de precipitação do Estado é maior [10], onde ocorre, portanto, uma maior diluição dos contaminantes na água do rio, evidenciado pelas taxas menores de $\mathrm{MN}$ encontradas. Entretanto, quando comparadas entre si (Figura 2), pode-se observar que no mês de Agosto houve uma maior frequência de células com MN; neste período as chuvas são menos frequentes, quando comparado ao mês de maio, cuja precipitação foi de $142.9 \mathrm{~mm}$ [11]. O ponto de coleta 1 apresentou em ambas coletas um percentual maior quando relacionado aos outros pontos, devido a sua localização em uma área mais vulnerável a ações antrópicas, estando mais próximo da cidade de São Cristóvão como mostra a Figura 1 e ao conjunto de habitações, onde ocorre despejo de lixo doméstico.

Os MNs, fragmentos ou cromossomos perdidos, entram no citoplasma e assumem a forma de um pequeno núcleo na intérfase seguinte [6]. Todo evento que altera o DNA e/ou o cromossomo pode levar ao desenvolvimento de um processo cancerígeno. O TMN destaca-se entre os ensaios biológicos para o monitoramento de risco carcinogênico [12].

O bivalve Mytella falcata, utilizado no estudo como bioindicador de impacto no DNA, tem sido pouco utilizado em avaliações de impacto genotóxico, mesmo se considerado sua ampla distribuição no Brasil. O presente estudo demonstrou ser um bom instrumento para avaliação mutagênica de ambientes impactados.

Trabalhos relacionados com Teste de Micronúcleo em Mytella falcata são escassos na literatura. Entretanto outros estudos utilizando mexilhões de outras espécies, demonstram eficácia do teste, apresentando resultados significativos para avaliações genotóxicas, tais com o de Geremia (2015) [13] e Silveira et al. (2003) [14] que corroboram para o uso desta técnica para monitoramento ambiental.

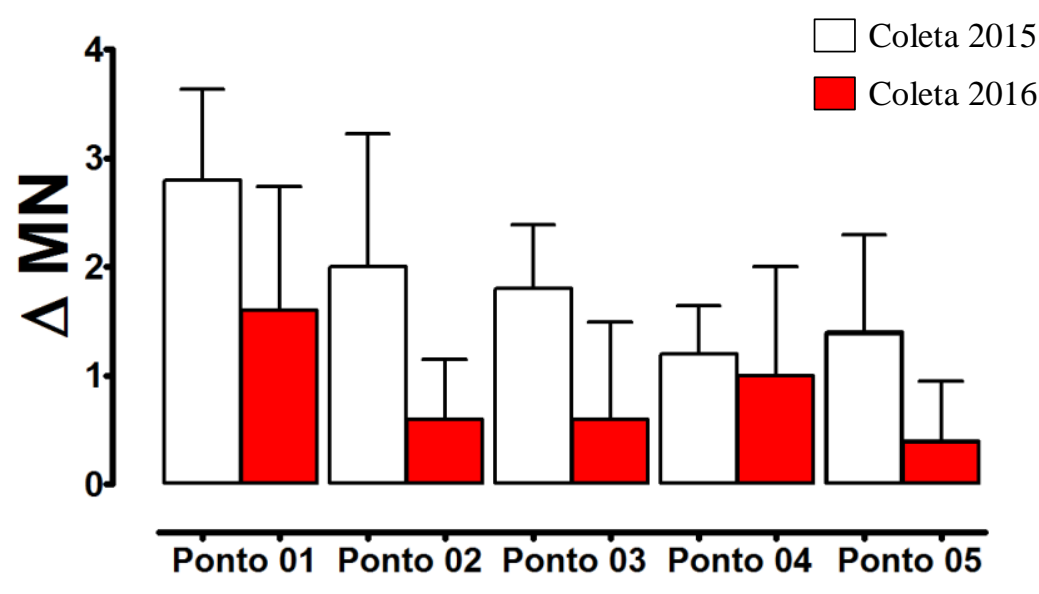

Figura 2. Distribuição de frequência de micronúcleos entre os cinco pontos observados. A primeira barra refere-se ao ano de 2015 e a segunda ao ano de 2016.p>0,005, Two-way ANOVA seguido do pós teste de Bonferroni 


\section{CONCLUSÃO}

O presente estudo demonstrou a boa aplicabilidade do Teste de Micronúcleo em Mytella falcata para avaliação de ambientes impactados, pelo aumento na frequência de MN nos indivíduos testados, principalmente no ponto 1, em virtude da maior proximidade à cidade de São Cristóvão-SE, que gera uma vulnerabilidade ambiental devido as ações antrópicas. Este fato permite concluir que há impacto de poluentes mutagênicos no Rio Paramopama sobre o DNA dos animais ali residentes. Para populações humanas que utilizam Mytela Falcata na alimentação tradicional, como é o caso na Região Nordeste, o impacto da poluição chega indiretamente, ampliando o risco de respostas biológicas adversas e mesmo doenças. $\mathrm{O}$ uso de modelos biológicos, como no caso de moluscos bivalves, representa, além disso, importante ferramenta para a avaliação das condições de saúde de ambientes aquáticos, assim como na geração de dados científicos que possam ser utilizados para a formulação de políticas públicas de conservação ambiental.

\section{REFERÊNCIAS BIBLIOGRÁFICAS}

1. Silva R. Poluição: lixo, esgoto e metais pesados ameaçam os rios do Brasil. Tera ambiental, 2014 [acesso em 20 maio 2016]. Disponível em: http://www.teraambiental.com.br/blog-da-teraambiental/poluicao-lixo-esgoto-e-metais-pesados-amea\%C3\%A7am-os-rios-do-brasil.

2. Villela IV, Lau A, Silveira J, Prá D, Rolla HC, Silveira J de D. Bioensaios para Monitoramento de Genotoxicidade Ambiental. In: Silva da J, Erdtmann B, Henriques JAP. Genética Toxicológica. Porto Alegre. Editora Alcance, 147- 163, ISBN-13: 9788575920114.

3. Bolognesi C, Rabboni R, Roggieri P. Genotoxicity Biomarkers in M. galloprovincialis as Indicators of Marine Pollutants. Comp Biochem Physiol, 1996;113(2):319-323, doi:10.1016/0742-8413(95)021035.

4. Carvalho GP de, Cavalcante PRS, Castro ACL de, Rojas MOAI. Preliminary assessment of heavy metal levels in Mytella falcata (Bivalvia, Mytilidae) from Bacanga River estuary, São Luis, State of Maranhão, Northeastern Brazil. Rev Bras Biol. São Carlos, 2000;60(1):11-16, doi:10.1590/S003471082000000100003

5. Bolognesi C, Hayashi M. Micronucleus assay in aquatic animals. Mutagenesis. 2011;26:205-213, doi:10.1093/mutage/geq073.

6. David JA de O, Salaroli RB, Fontanetti CS. The significance of changes in Mytella falcata. (Orbigny, 1842) gill filaments chronically exposed to polluted environments, Micron, Volume [periódicos na internet], 2008; 1293-1299 [acesso jul 2015]. Disponível em: http://www.sciencedirect.com/science/article/pii/S0968432808000735.

7. Bacias Hidrográficas no Estado de Sergipe, 2011 [acesso em 06 dez 2015]. Disponível em: http://www.redeacqua.com.br/2011/03/bacias-hidrograficas-do-estado-de-sergipe/.

8. Carvalho MES. Vulnerabilidade Hídrica na Bacia Sergipana do Rio Vaza Barris, Raega. 2012;25:186217, doi:10.5380/raega.v25i0.28011 10.5380/raega.v25i0.28011.

9. Baršienė J, Dedonyte V, Rybakovas A, Andreikenate L, Andersen Odd-Ketil. Induction of micronuclei in Atlantic cod (Gadus morhua) and turbot (Scophthalmus maximus) after treatment with bisphenol A, diallyl phthalate and turbot in mussels exposed to bisphenol A, diallyl phthalate and tetrabromodiphenyl ether-47. Ekologija. 2005;4:1-7.

10. Instituto Nacional de Pesquisas Espaciais, Centro de previsão do Tempo e Estudos Climáticos. Índice de Precipitação Padronizado (SPI), 2016 [acesso em 21 maio 2017]. Disponível em: http://clima1.cptec.inpe.br/spi/pt.

11. Boletim Climatológico Mensal. Maio, 2016 [acesso Set 2017]. Disponível em: https://www.ipma.pt/resources.www/docs/im.publicacoes/edicoes.online/20160606/BouXpNiHpWTK JsUladlE/cli_20160501_20160531_pcl_mm_co_pt.pdf.

12. Rodrigues RO, Moreira LMA, Silva, EJS, Trindade JPB, Rocha LM, Espírito Santo LD, Moreira SC. Ensaio do micronúcleo como indicador de genotoxicidade em indivíduos com albinismo e historic prévio de cancer de pele. Rev Ciênc Méd Biol, Salvador. 2013;12(2):194-197.

13. Geremia G. Análise de micronúcleos em hemócitos de mexilhões Perna perna (Linnaeus, 1758) (Mollusca: Bivalvia: Mytilidae) nas plataformas de pesca de Tramandaí e Cidreira, litoral norte do Rio Grande do Sul, Brasil. IMBÉ, 2015. [acesso Set 2017]. Disponível em: https://www.lume.ufrgs.br/bitstream/handle/10183/140094/000984639.pdf?sequence=1. 
14. Silveira J, Villela IV, Oliveira IM, Silva J, Henriques JAP. A utilização do mexilhão dourado (Limnoperna fortunei (Dunker, 1857)) como biomonitor de genotoxicidade ambiental. Revista de Iniciação Científica da ULBRA. 2003;2:83-93. 